\title{
Acute respiratory distress syndrome ("ARDS"): no more than a severe acute lung injury?
}

\author{
Richard Beale, E Robert Grover, Mark Smithies, David Bihari
}

The term "ARDS" was introduced in 1967, when Ashbaugh et al reported a syndrome of acute respiratory distress in adults." They described 12 comparatively young patients, one of whom was a child, who had developed acute respiratory failure which seemed to follow a common course. It was said to have occurred in response to various stimuli, but in fact seven of the patients had suffered multiple trauma. Each case was characterised by severe arterial hypoxaemia refractory to oxygen, reduction in lung compliance, and bilateral diffuse alveolar infiltration in the chest $x$ ray film. The oxygenation defect was partially responsive to positive end expiratory pressure but in seven cases seemed to be related to strongly positive fluid balance. Postmortem examination disclosed alveolar atelectasis, widespread inflammatory changes, and hyaline membranes. Four years later, in a second paper, the same authors used the term "adult respiratory distress syndrome." Hence the confusion about what the A in ARDS stands for was born.

Since the original description the diagnostic criteria have been modified to emphasise that the pulmonary oedema which occurs is non-cardiogenic and due to an increase in pulmonary capillary permeability. ${ }^{3}$ A pulmonary artery occlusion pressure of less than $18 \mathrm{~mm} \mathrm{Hg}$ is required to allow differentiation between the acute respiratory distress syndrome and the pulmonary oedema of acute heart failure and fluid overload. Nevertheless, research has been bedevilled by conflicting and insufficiently precise definitions. More recently, the broader label "acute lung injury" has been introduced to describe the full range (including the less severe forms) of acute respiratory failure associated with the recognised risk factors for the acute respiratory distress syndrome (box 1$){ }^{4}$

Department of Surgery, Guy's Hospital, London SE1 9RT

Richard Beale, honorary senior registrar

E Robert Grover, honorary senior registrar

Department of Intensive Care, Guy's Hospital, London SE1 9RT

Mark Smithies, consultant in intensive care

David Bihari, physician in charge

Correspondence to: Dr Bihari.

$B M F$ 1993;307:1335-9

\begin{tabular}{l} 
Summary points \\
\hline - The generic term acute lung injury is prefer- \\
able to the acute respiratory distress syndrome, \\
which should be applied to only the most severe \\
forms of respiratory failure \\
- Although fairly rare in general intensive care \\
units, the condition has a high mortality (60\%) \\
- Increased pulmonary capillary permeability \\
is responsible for the pulmonary oedema that \\
occurs \\
- The first principle of management is to \\
diagnose and treat the cause \\
- Treatment is aimed at achieving adequate gas \\
exchange without exacerbating injury to the \\
lung; finding the optimal pattern of ventilation \\
may be difficult \\
- Likelihood of developing acute respiratory \\
distress syndrome increases with the number of \\
risk factors for the condition
\end{tabular}

yearly incidence of the condition of 1.5 cases per 100000 population. Using less stringent criteria of $\mathrm{PaO}_{2}<10 \mathrm{kPa}$ and $\mathrm{FiO}_{2}>0.5$ (equivalent to $\mathrm{PaO}_{2}: \mathrm{FiO}_{2}$ ratio $<20 \mathrm{kPa}$ ), the authors still found an incidence of only 3.5 cases per 100000 population a year.

This estimate has been confirmed by more recent surveys in North America, ${ }^{7}$ Britain, ${ }^{8}$ and Germany. ${ }^{9}$ The APACHE III study of 17440 intensive care admissions to $\mathbf{4 0}$ hospitals in North America identified only 323 patients $(1.9 \%)$ who had an acute lung injury on admission (defined as acute respiratory distress on admission with a $\mathrm{PaO}_{2}: \mathrm{FIO}_{2}$ ratio $<40 \mathrm{kPa}$ and a discharge diagnosis of the acute respiratory distress syndrome. ${ }^{10}$ Thus true acute respiratory distress syndrome that evolves from an acute lung injury seems to be fairly rare in general intensive care units.

Difficulties in case definition have also been responsible for the debate regarding survival from the condition. In the original report seven of the 12 patients died. ${ }^{1}$ A European multicentre study of 583 patients with the acute respiratory distress syndrome recorded an overall mortality of $59 \%,{ }^{11}$ which accords well with findings in other studies. The suggestion that mortality had not changed for 25 years was unlikely to be true ${ }^{12}$ and reflected the changing case mix. Patients treated today are likely to be older, to be sicker, and to have more chronic health problems. Moreover, hypoxaemic respiratory failure is not now a frequent cause of death, most patients dying of multiple organ failure. ${ }^{13}$ Survival in patients with the 


\section{Box 1-Risk factors associated with development of acute lung injury and acute respiratory distress syndrome ${ }^{\star}$}

Direct injuries
- Infection
- Aspiration
- Bruising
- Inhalation (smoke and other noxious gases)
- Stress failure of pulmonary capillaries
- Near drowning
Indirect injuries
- Sepsis
- Multiple trauma
- Fat embolism
- Disseminated intravascular coagulation
- Prolonged hypotension
- Acute pancreatitis
- Cardiopulmonary bypass
- Multiple transfusions
- Drugs and toxins-for example, heroin, salicylates,
paraquat

- Multisystem diseases-for example, vasculitis, thrombotic thrombocytopenia purpura, acute hepatic failure

${ }^{\star}$ Likelihood of developing acute respiratory distress syndrome increases with number of risk factors- $25 \%$ with one risk factor, $42 \%$ with two risk factors, $85 \%$ with three risk factors.

acute respiratory distress syndrome, as confirmed by the European study, ${ }^{11}$ seems to be primarily dependent on the age of the patient, whether the patient responds to treatment in the first 24 hours, and the underlying cause of lung injury (survival is better in patients with trauma than in those with aspiration or infection). ${ }^{14}$

To overcome some of these difficulties a North American-European consensus group was recently established in order to standardise the various definitions used. The conclusions of the group, soon to be published, include the following: "ARDS must be the ACUTE respiratory distress syndrome since the condition can occur in children."15 The generic term acute lung injury, representing a continuum of radiological and blood gas abnormalities in the appropriate clinical setting, is preferred to the acute respiratory distress syndrome, which should be applied to only the most severe forms of respiratory failure (box 2). When considering prognosis and designing clinical trials it is crucial to stratify patients by (a) pulmonary gas exchange defect (carefully noting the presence or absence of positive intrathoracic pressure), (b) the number of other organ system failures, $(c)$ the cause of the acute lung injury, and (d) any associated disease that may materially influence life expectancy.

\section{Mechanisms of acute lung injury}

The mechanisms by which an acute lung injury develops are unclear. Damage may be a consequence of direct injury or it may occur indirectly-for example, as a result of a generalised systemic acute inflammatory process in which the lung is one of many target organs. This second setting is often associated with sepsis and multiple trauma. Much effort has been applied to delineating the roles of inflammatory cellsneutrophils, monocytes, alveolar macrophages, together with platelets-and their mediators released both locally in the lung and systemically into the venous blood of infected or ischaemic tissues. The latter may explain why the lungs of critically ill patients are so often injured-not only is the endothelium of the pulmonary circulation the first to come into contact with this contaminated venous blood but it is also exposed to the entire venous effluent of the patient.

CELLS AND MEDIATORS IN THE ACUTE RESPIRATORY DISTRESS SYNDROME

Microscopical examination of the lung in acute lung injury shows large numbers of neutrophils and degranulated platelets and widespread endothelial damage. Repine suggested that activated neutrophils adhere to endothelial cells and release inflammatory oxygen free radicals and various proteases (including elastase), which contribute to lung damage. ${ }^{16}$ This may be so in most cases but the acute respiratory distress syndrome also occurs in patients who are neutropenic, ${ }^{17}$ which emphasises the multiplicity of the mechanisms concerned. Clearly, direct lung damage and endothelial injury from endotoxin alone will stimulate the release of cytokines with further amplification of an inflammatory response. It is difficult to interpret the increasing number of reports ${ }^{18}{ }^{19}$ concerning the identification of inflammatory mediators in bronchoalveolar lavage fluid, as this presumably reflects only one aspect of the process and is unlikely to hold any immediate prospect for specific immunological intervention.

\section{VENTILATOR INDUCED LUNG INJURY}

Positive pressure ventilation is virtually always employed in the acute respiratory distress syndrome because by increasing the transpulmonary distending pressure (mean airway pressure minus pleural pressure) it is the most readily available means of improving arterial oxygenation. An adequate distending pressure is thought to reinflate less diseased but collapsed alveoli through "recruitment," hence reducing the mismatch of perfusion to ventilation. ${ }^{20}$ Unfortunately, the distending pressure and the volume generated may themselves contribute to further lung injury. Excessive ventilation pressures are associated with both haemodynamic disturbances and pulmonary barotrauma

\section{Box 2-Definitions of acute lung injury and} acute respiratory distress syndrome

- Appropriate clinical setting with one or more recognised risk factors

- Bilateral diffuse fluffy infiltrates in chest radiograph ${ }^{\star}$

- No clinical evidence of heart failure, fluid overload, or chronic lung disease $\nmid$

Acute lung injury

- Abnormalities in pulmonary gas exchange as defined by $\mathrm{PaO}_{2}: \mathrm{FiO}_{2}$ ratio $<40 \mathrm{kPa} \ddagger$

\section{Acute respiratory distress syndrome}

- Severe abnormalities in pulmonary gas exchange as defined by $\mathrm{PaO}_{2}: \mathrm{FIO}_{2}$ ratio $<20 \mathrm{kPa} \ddagger$

*Abnormal chest $x$ ray appearances may lag behind functional disturbances.

†Patients with chronic lung disease must be excluded as they may have abnormal chest $x$ ray appearances and severe disturbances in pulmonary gas exchange before any acute insult is recorded.

$\ddagger$ Positive pressure ventilation (continuous positive airway pressure or ventilation with positive end expiratory pressure) may profoundly affect this measurement, and its presence or absence must be carefully recorded. 
(box 3), yet there are wide variations in the maximum inflation pressures used in clinical practice.

In animals it is possible to reproduce the pathological changes of the acute respiratory distress syndrome merely by using peak inflation pressures of $2.9 \mathrm{kPa}$ $\left(30 \mathrm{~cm} \mathrm{H}_{2} \mathrm{O}\right)$ and $3.9 \mathrm{kPa}\left(40 \mathrm{~cm} \mathrm{H}_{2} \mathrm{O}\right)$ and so generating high tidal volumes. ${ }^{22}{ }^{22}$ Yet if the chest of an animal is banded, thereby reducing total thoracic compliance, high airway pressures give only low tidal volumes, and this form of ventilation does not cause lung damage. ${ }^{23}$ Volume rather than pressure seems to be the critical variable, and it may be that much of the common pathological change seen in the acute respiratory distress syndrome of whatever cause is due to "volutrauma"-iatrogenic attempts to squeeze an excessive volume into lungs which have greatly reduced capacity.

More evidence for this mechanism comes from computed tomography of the chest in patients with the acute respiratory distress syndrome. Though the images produced emphasise the patchy nature of the damage (figure), the typical appearance is of increased density consistent with poorly or non-aerated tissue in the dependent part of the lung. Changes in the computed tomogram in response to positive end expiratory pressure or a shift of the patient from supine to prone suggest that certainly part of the reduction in the gas to tissue ratio seen at the lung bases is not so much true consolidation but rather collapsed lung compressed by the weight of the oedematous diseased lung above. ${ }^{24}$

Positive end expiratory pressure seems to modify the effect of tidal ventilation in different ways depending on the nature of the lung units to which it is applied. Thus Gattinoni et al suggest that the lungs in the acute respiratory distress syndrome can be divided into three sectors-a much reduced portion of comparatively undamaged lung (so called "baby lung"), which receives the bulk of the ventilation; an area of injured and collapsed lung which may be amenable to recruitment with appropriate ventilation; and an area of consolidated and necrotic lung which is not available for ventilation. ${ }^{25}$ It follows that the typical tidal volume $(8-15 \mathrm{ml} / \mathrm{kg})$ used when ventilating patients with an acute lung injury (which may be reasonable when ventilating patients with normal lungs) is actually being directed to the much smaller amount of lung which is either still normal or is damaged but has been recruited. The dangers of further volutrauma are plain, animal studies showing that such hyperinflation is itself associated with progressive destruction of normal lung.

Finally, the effects of a raised inspired oxygen concentration should not be forgotten. Though high inspired oxygen concentrations can cause similar pathological lesions, ${ }^{26}$ this effect is now thought to be less relevant than that of excessive volume. Indeed, there is little or no consensus in clinical practice about a time weighted maximum limit for the inspired oxygen fraction. ${ }^{27}$

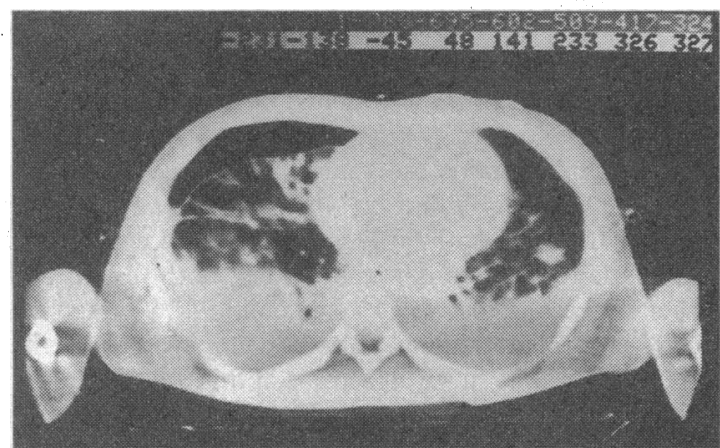

Thoracic computed tomogram in patient with severe acute respiratory distress syndrome showing pronounced opacities in dependent regions of lung and anterior pneumothorax on right
Box 3-Undesirable effects of excessive positive intrathoracic pressure*

Haemodynamic effects

- Reductions in cardiac output due to reduced venous return, increased pulmonary vascular resistance, and ventricular septal shift

- Reductions in renal, hepatic, and splanchnic blood flow

- Decrease in cerebral perfusion pressure

- Effects on antidiuretic hormone, atrial natriuretic peptide, and aldosterone secretion, leading to sodium and water retention

\section{Effects on lung tissue}

- Pulmonary barotrauma

-interstitial emphysema

-pneumomediastinum

- subcutaneous emphysema

-pneumothorax

- Reduction in lymphatic flow

Increase in shear stress on pulmonary capillaries

^Especially common in patients with unmeasured and excessive gas trapping and occult positive end expiratory pressure.

\section{Management of acute lung injury}

The first principle in management of an acute lung injury is to make a diagnosis and treat the cause. Without drainage of the intra-abdominal abscess, excision of the dead bowel, or appropriate antimicrobial agents for the pneumonia the patient will die. Adequate resuscitation guided by invasive haemodynamic monitoring, including pulmonary artery catheterisation, is essential to prevent multiple organ failure. Fluids (colloid and crystalloid), inotropes, and blood should be given to maintain an adequate mean arterial pressure, a cardiac output sufficient to reverse global tissue hypoxia (as defined by a lactic acidosis), and a haemoglobin concentration greater than $120 \mathrm{~g} / \mathrm{l}$. There is also evidence that attention to regional (especially splanchnic) perfusion may be valuable in the detection and treatment of tissue hypoxia that is not readily identified by any other means. ${ }^{28}$

The importance of appropriate fluid management is much emphasised. In the presence of increased pulmonary capillary permeability hydrostatic pressure is the most important determinant of fluid movement into the lungs, and our guiding principle is to manage these patients with the lowest possible pulmonary artery occlusion pressure that is consistent with an adequate cardiac output. Lung water can now be measured at the bedside, and a very high value is associated with a poor outcome. ${ }^{29}$ Fluid removal by diuresis or haemofiltration, however, may not reduce lung water while a capillary leak persists. In addition, the use of vasoconstrictors may increase lung water by raising pulmonary capillary pressure. The strategy of aggressively "drying out" such patients in order to improve gas exchange while supporting the circulation with vasoconstrictors may seem logical but is not supported by sound measurement and data. It is probably more important not to give too much fluid in the first place and to await the oedema mobilisation that accompanies lung healing.

Pulmonary hypertension and whether to treat it is another vexed issue. ${ }^{30}$ It is thought to be a consequence of mediator release (specifically thromboxane $A_{2}$ ), hypoxic pulmonary vasoconstriction, and direct vessel compression. At high blood flows capillary filtration pressure is closer to the mean pulmonary artery pressure than to the pulmonary artery occlusion 
pressure. ${ }^{31}$ Thus efforts to reverse pulmonary hypertension-for example, with $\beta_{2}$ agonists, epoprostenol, or nitric oxide-may be important not only in reducing the likelihood of right ventricular dysfunction but also in limiting oedema formation.

Once general resuscitation has been carried out specific treatment of the injured lungs can be started. Management has two main but conflicting aims. The first is to achieve adequate gas exchange so as to prevent the patient from dying of arterial hypoxaemia and respiratory acidosis. The second is to treat the lungs in a way that does not exacerbate the injury. Mechanical ventilation is the mainstay and is undoubtedly lifesaving in many cases. But any death that ensues begs the question whether the so called treatment was contributory.

\section{Ventilatory strategy in acute lung injury}

The first requirement in an acute lung injury is to set realistic and achievable gas exchange targets that do not result in an excessive tidal volume and intrathoracic pressure. Given that a gradual increase in arterial carbon dioxide pressure does not seem to be harmful in itself, the lowest inspired oxygen fraction and peak inspiratory pressure possible that will maintain arterial oxygenation (arterial saturation $>85-90 \%$ ) and prevent a severe respiratory acidosis $(\mathrm{pH}<7 \cdot 20)$ should be used..$^{32}$ In general spontaneous modes of respiratory support (continuous positive airway pressure, pressure support, volume support) are preferred, but patients who have severe abnormalities in pulmonary gas exchange and greatly reduced compliance usually end up requiring controlled ventilation with sedation and, on occasion, muscle relaxants.

Pressure controlled ventilation seems to be superior to volume control. ${ }^{33}$ This may be related in part to the continuous but decelerating gas flow that occurs in pressure controlled ventilation throughout the inspiratory phase. Given the great variation within injured lung in the time required to fill alveoli, pressure controlled ventilation results in a better distribution of gas and a higher mean airway pressure for any given peak pressure. Positive end expiratory pressure (5-15 $\mathrm{cm} \mathrm{H}_{2} \mathrm{O}$ ) and the inspiratory time (and thus the inspiratory to expiratory ratio) are adjusted to set the mean airway pressure, the primary determinant of alveolar recruitment and arterial oxygenation. The inspiratory time may be lengthened (thus reversing the inspiratory to expiratory ratio from the normal $1: 2$ to $1: 1,2: 1$, or even $3: 1$ ) so as to increase the mean airway pressure while limiting the peak. The dangers of this manoeuvre are gas trapping and excessive occult positive end expiratory pressure ("auto PEEP"), which may well result in barotrauma or a sudden haemodynamic deterioration. Airways resistance is nearly always increased in an acute lung injury and bronchodilators may help reduce gas trapping. ${ }^{34}$ In any event, it is important to measure the amount of positive end expiratory pressure ${ }^{35}$ and to take it into account when adjusting the set pressure.

In practice, finding the optimal pattern of ventilation for a critically ill patient with the acute respiratory distress syndrome requires considerable skill in balancing the demand for positive pressure against its detrimental effects on the circulation and healthy lung tissue. It is important to appreciate that the optimal pattern will change in any given patient, presumably reflecting the changing disease process. For this reason, it is difficult to perform controlled clinical trials, and at present there is no evidence that survival is materially influenced by any one form of ventilation. Nevertheless, we and many other European specialists believe that pressure controlled inverse ratio ventilation is the best means of supporting these patients.

\section{New methods of respiratory support}

HIGH FREQUENCY VENTILATION

Various forms of high frequency ventilation have been advocated ${ }^{36}$ and the newer systems have overcome the difficulties with humidification. It seems that any improvements in oxygenation achieved are due to an increase in mean airway pressure and the generation of occult positive end expiratory pressure. High frequency ventilation has been associated with an appreciable amount of barotrauma in the form of pneumothoraces. The role of this type of ventilation in an acute lung injury remains unclear.

\section{NITRIC OXIDE}

Nitric oxide selectively dilates pulmonary vessels in ventilated areas of lung when given by inhalation. Unlike other pulmonary vasodilators (which cannot be delivered to ventilated areas of lung alone), nitric oxide therefore reduces pulmonary shunt. Moreover, as nitric oxide is rapidly inactivated by haemoglobin, it has no systemic effects. In a series of 10 patients with the acute respiratory distress syndrome Rossaint et al reported that short term administration of nitric oxide at $18 \mathrm{ppm}$ and $36 \mathrm{ppm}$ reduced pulmonary artery pressure, decreased intrapulmonary shunting, and improved oxygenation without any systemic haemodynamic effects. ${ }^{37}$ In contrast, epoprostenol reduced pulmonary artery pressure but increased the shunt and reduced arterial oxygen pressure. Epoprostenol also reduced systemic arterial pressure and increased cardiac output. Seven of the 10 patients received nitric oxide at 5-20 ppm for between three and 53 days, and overall eight survived. Of note, however, was the age of these patients-17-46 years (17-24 in those receiving prolonged nitric oxide). Nine had direct pulmonary injury and five received extracorporeal support.

Though these results represent a formidable achievement, it is not clear what contribution nitric oxide made to survival. In our hands, and in older patients with the acute respiratory distress syndrome as a complication of sepsis, we have observed the same pharmacological effects with nitric oxide but the outcome has been much less encouraging. ${ }^{38}$

\section{EXOGENOUS SURFACTANT}

Currently, there is considerable interest in the use of exogenous surfactant to replace surfactant that is thought to be lost in an acute lung injury. ${ }^{39}$ It may be that surfactant replacement, which has become an accepted treatment for respiratory distress associated with premature birth, will improve pulmonary compliance in any patient (adult or child) with the acute respiratory distress syndrome. Phase III trials are in progress.

\section{EXTRACORPOREAL LUNG SUPPORT AND INTRAVENOUS} OXYGENATION

Extraordinary means of sustaining life in patients with the acute respiratory distress syndrome include extracorporeal lung support and intravenous oxygenation. Various forms of extracorporeal lung support have been used in patients with an acute lung injury since the $1970 \mathrm{~s}$. Though not initially successful, their use in adults has continued in a few European and North American centres. Extracorporeal lung support is now usually employed in the venovenous form and provides both extra carbon dioxide clearance and oxygenation. ${ }^{40}$ Though many initial technical problems have been overcome, there have been no controlled trials of this treatment.

Intravenous oxygenation is accomplished by means of an implantable oxygenation device-intravenous oxygenator-placed percutaneously via the femoral vein into the inferior vena cava. Though exciting, 
preliminary experience suggests that its gas exchange capacity is still too limited to provide useful respiratory support (see editorial p 129341)..$^{424}$

\section{Steroids}

Though steroids have no role in the routine management of an acute lung injury, a few patients may benefit in the more chronic phase of their illness. ${ }^{44} 45$ It remains our practice to consider initiating steroids after two to three weeks of mechanical ventilation in patients who continue to have signs of severe acute inflammation (in particular, fever and a high carbon dioxide production) in the absence of any proved source of infection.

\section{Conclusion}

Nowadays, much can be done for patients with a severe acute lung injury. We believe that in the best centres many patients survive who previously would have died. It is the attention to detail-making a diagnosis, aggressive resuscitation, treating any underlying infection, and establishing the most effective and least harmful form of ventilation-which is paramount. The acute respiratory distress syndrome is no more than a severe acute lung injury, but it is often associated with a systemic process that may cause widespread tissue injury. Hence any new respiratory treatment on its own is unlikely to have much impact on survival. Attention must centre on preventing ventilator induced lung damage and other organ failure together with modulation of the acute inflammatory process.

We are grateful to Professor L Gattinoni for the thoracic computed tomogram

1 Ashbaugh DG, Bigelow DB, Petty TL, Levine BE. Acute respiratory distress in adults. Lancet 1967 ;ii:319-23.

2 Petty TL Ashbaugh DG. The adult respiratory distress syndrome: clinical features, factors influencing prognosis and principles of management. Chest 1971;60:233-9.

3 Robin ED, Carey LC, Grenvik A, Glauser F, Gaudio R. Capillary leak syndrome with pulmonary edema. Ann Intern Med 1972;130:66-7

4 Hyers T, Fowler A. Adult respiratory distress syndrome: causes, morbidity and mortality. Federation Proceedings 1986;45:25-9.

5 National Heart and Lung Institutes. Respiratory diseases. Task force report on problems, research approaches, needs. Washington, DC: US Government Printing Office, 1972:167-80. (DHEW publication NIH 74-432.)

6 Villar J, Slutsky AS. The incidence of the adult respiratory distress syndrome. Am Rev Respir Dis 1989;140:814-6.

7 Thomesen GE, Morris AH, Danino D, Ellsworth J, Wallace CJ. Incidence of adult respiratory distress syndrome in Utah (abstract). Am Rev Respir Dis 1993;147(suppl):A347.

8 Webster NR, Cohen AT, Nunn JF. Adult respiratory distress syndromehow many cases in the UK? Anaesthesia 1988;43:923-6.

9 Lewandowski K, Metz J, Preib H, et al. Incidence, severity and mortality of acute respiratory failure in Berlin, Germany: a prospective multi-center tria in 72 intensive care units (abstract). Am Rev Respir Dis 1993;147(suppl): A349.

10 Knaus WA, Wagner DP, Draper EA, Zimmerman JF, Bergner M, Bastos PG et al. The APACHE III prognostic system. Risk prediction of hospita mortality for critically ill hospitalized adults. Chest 1991;100:1619-36.

11 Artigas A, Carlet J, Chastang C, Flandre P, Le Gall JR, and European ARDS Collaborative Working Group. Clinical presentation, etiology, prognostic factors and outcome of the adult respiratory distress syndrome. Reanimation Soins Intensif Medicin Urgences 1988;4:339-45.

12 Rinaldo J. The prognosis of the adult respiratory distress syndromeinapropriate pressimism? Chest 1986;90:470-1.

13 Montgomery AB, Stager MA, Carrico CA, Hudson DL. Causes of mortality in patients with the adult respiratory distress syndrome. Am Rev Respir Dis 1985;132:485-9.

14 Artigas A, Carlet J, Le Gall J-R, Chastang CL, Blanch L, Fernandez R Clinical presentation, prognostic factors and outcome of ARDS in the European collaborative study (1985-1987) -a preliminary report. In: Zapol WM, Lemaire F, eds. Adult respiratory distress syndrome. New York: Marcel Dekker, 1991:37-63.

15 Timmons OD, Dean JM, Vernon DD. Mortality rates and prognostic variables in children with adult respiratory distress syndrome. 7 Pediatr 1991;119:896-9.

16 Repine JE. Scientific perspectives on adult respiratory distress syndrome. Lancet 1992;339:466-9.

17 Ognibene FP, Martin SE, Parker MM, Schlesinger T, Roach P, Burch C, et al. Adult respiratory distress syndrome in patients with severe neutropenia. $N$ Engl f Med 1986;315:547-51.

18 Suter PM, Suter S, Girardin E, Roux-Lombard P, Grau G, Dayer JM High bronchoalveolar levels of tumor necrosis factor and its inhibitors, interleukin-1, interferon, and elastase, in patients with adult respiratory distress syndrome after trauma, shock or sepsis. Am Rev Respir Dis 1992;145:1016-22.

19 Donnelly SC, Strieter RM, Kunkel SL, Walz A, Robertson CR, Carter DC, et al. Interleukin-8 and the development of adult respiratory distress syndrome in at-risk patient groups. Lancet 1993;341:643-6.

20 Wagner PD, Rodriguez-Roison R. Clinical advances in pulmonary gas exchange. Am Rev Respir Dis 1991:143:883-8.

21 Tsuno $K$, Prato $P$, Kolobow $T$. Acute lung injury from mechanical ventilation at moderately high pressures. 7 Appl Physiol 1990;69:956-61.

22 Tsuno K, Miura K, Takeya M, Kolobow T, Morioka T. Histopathologic pulmonary changes from mechanical ventilation at high peak airway pressures. Am Rev Respir Dis 1991;143:1115-20.

23 Dreyfuss D, Saumon G. Barotrauma is volutrauma but which volume is the one responsible? Intensive Care Med 1992;18:139-41.

24 Gattinoni I, Pelosi P, Vitale G, Pesenti A, D'Andrea L, Mascheroni D. Body position changes redistribute lung computed-tomographic density in patients with acute respiratory failure. Anesthesiology 1991;74:15-23.

25 Gattinoni L, D'Andrea L, Pelosi P, Vitale G, Pesenti A, Fumagalli R. Regional effects and mechanism of positive end-respiratory pressure in early adult respiratory distress syndrome. $7 A M A$ 1993;269:2122-7.

26 Deneke SM, Fanburg BL. Normobaric oxygen toxicity of the lung. $N$ Engl f Med 1980;303:76-85

7 Lodato RF. Oxygen toxicity. Crit Care Clin 1990;6:749-65.

28 Maynard N, Bitari D, Beale R, Smithies M, Baldock G, Mason $R$, et al. Assessment of splanchnic oxygenation by gastric tonometry in patients with acute circulatory failure. $¥ A M A$ (in press).

29 Mitchell JP, Schuller D, Calandrino FS, Schuster DP. Improved outcome based on fluid management in critically ill patients requiring pulmonary artery catheterization. Am Rev Respir Dis 1992;145:990-8.

30 Grover ER, Bihari D. Acute pulmonary hypertension in the critically ill. Respir Physiol (in press).

31 Younes $\mathrm{M}$, Bshouty $\mathrm{Z}$, Ali J. Longitudinal distribution of pulmonary vascular resistance with very high pulmonary blood flow. I Appl Physiol 1987;62 344-58.

32 Hickling KG, Henderson SJ, Jackson R. Low mortality associated with permissive hypercapnia in severe adult respiratory distress syndrome. Intensive Care Med 1990;16:372-7.

33 Lain DC, DiBenedetto R, Morris SL, Nguyen AV, Saulters R, Causey D. Pressure control inverse ratio ventilation as a method to reduce peak Pressure control inverse ratio ventilation as a method to reduce peak inspiratory pressure and
Chest 1989;95:1081-8.

34 Pesenti A, Pelosi P, Rossi N, Aprigliano M, Brazzi L, Fumagilli R Respiratory mechanics and bronchodilator responsiveness in patients with the adult respiratory distress syndrome. Crit Care Med 1993;21:78-83.

35 Pepe PE, Marini JJ. Occult positive end-expiratory pressure in mechanically ventilated patients with airflow obstruction: the auto-PEEP effect. $A m$ Rev Respir Dis 1982;126:166-70.

36 High frequency ventilation [editorial]. Lancet 1991;337:706-7.

37 Rossaint R, Falke KJ, Lopez F, Slama K, Pison U, Zapol WM. Inhaled nitric oxide for the adult respiratory distress syndrome. N Engl f Med 1993;328: 399-405.

38 Grover ER, Beale R, Smithies M, Bihari D. A dose profile of the physiological effects of inhaled nitric oxide in acute lung injury. Am Rev Respir Dis 1993;147(suppl):A350.

39 Lewis $\mathrm{F}$, Jobe AH. Surfactant and the adult respiratory distress syndrome. Am Rev Respir Dis 1993;147:218-33.

40 Villar J, Winston B, Slutsky AS. Non-conventional techniques of ventilatory support. Crit Care Clin 1990;6:579-603.

41 Sim KM, Evans TW. Supporting the injured lung. BMF 1993;307:1293-4.

42 High KM, Snider MT, Richard R, Russell GB, Stene JK, Cambell DB, et al. Clinical trials of an intravenous oxygenator in patients with adult respiratory distress syndrome. Anesthesiology 1992;77:856-63.

43 Zapol WM. Volotrauma and the intravenous oxygenator in patients with adul respiratory distress syndrome. Anesthesiology 1992;77:847-9.

44 Meduri GU, Belenchia JM, Estes RJ, Wunderink R, El Torky M, Leeper KV. Fibroproliferative phase of ARDS; clinical findings and effects of corticosteroids. Chest 1991;100:943-52.

45 Chinn A, Meduri GU, Leeper K, Wunderink R, Nathaniel A, El Torky M High dose corticosteroids for rescue treatment of fibroproliferation in late ARDS Am Rev Respir Dis 1993;147(suppl):A349.

\section{SOUND BITES}

\section{Assessment in community care}

"I know that I'm coping if the windows are clean" said Mrs Blackstock, a woman in her late 70 s living alone in a council flat in north London. She was being consulted about the kind of community support she would need if as her frailty increases, she is to be able to continue to

live on her own. She needs other help, too, but the state of her windows is her personal test of her own competence. From Tessa Jowell: Community care in London: the prospects. In Jane Smith (ed) London after Tomlinson, 1993. Available from the BMJ Bookshop, price $£ 8.95$. 